\title{
Comparison of efficacy of commercially available vs. freshly prepared salicylic acid peel in treatment of acne: a randomized open-label study
}

Dhwani Rathod ${ }^{1}$, Purna Pandya ${ }^{1 *}$, Ishan Pandya ${ }^{2}$, Gaurav Shah ${ }^{3}$, Rima Shah $^{4}$ and Bela Padhiyar ${ }^{1}$

\begin{abstract}
Background: Chemical peeling is increasingly used in dermatology nowadays. Salicylic acid peels have been widely used in Asian patients since long ago, but very few published literature is there focusing on the efficacy and safety of it in Asian population. This study was planned to compare the efficacy of salicylic acid (SA) peel either commercially available or freshly prepared in treatment of acne.

Methods: A prospective, randomized, open-label, parallel-group study was carried out in patients with acne. A total of 126 patients were randomized to receive $30 \%$ salicylic acid peel either commercially available (group $A, n=60$ ) or freshly prepared (group B, $n=63$ ). Assessment of acne lesions was done at baseline and at 2, 4, 6, 8, 10, and 12 weeks. Objective assessment was carried out using total acne score and subjective assessment using visual analog scale and were compared.

Results: Mean age of patients was $22.4 \pm 3.1$ years with female predominance. After six sessions with commercially available SA peel, reduction in average number of comedones was $88.45 \%(P=0.002)$, in inflammatory papules $89.16 \%$ $(P=0.01)$, in pustules $31.47 \%(P=0.06)$, and in nodules/cyst 50\% $(P=0.5)$. After six sessions with freshly prepared SA peel, reduction in average number of comedones was $89 \%(P=0.0001)$, in inflammatory papules $90.36 \%(P=0.0001)$, in pustules $28.3 \% \%(P=0.05)$, and in nodules $96 \%(P=0.05)$. Significant reduction of both non-inflammatory and inflammatory acne was seen in both groups $(P<0.05)$. Both of the agents led to a highly significant $(P<0.001)$ improvement in the total acne score; freshly prepared SA peel showed improvement significantly earlier at 6 weeks onwards. VAS score was significantly high for the freshly prepared SA group $(P=0.05)$.

Conclusion: This study has shown equivalence in therapeutic efficacy of both commercially available and freshly prepared SA peels both in terms of objective and subjective assessments in acne treatment with more patient satisfaction with freshly prepared peel.
\end{abstract}

Keywords: Acne, Salicylic acid peel, Commercially available vs. freshly prepared SA peel, Efficacy comparison, Total acne score

\footnotetext{
* Correspondence: dr.purnapandya2017@gmail.com

'Department of Dermatology, GMERS Medical College, Gandhinagar, Gujarat,

India

Full list of author information is available at the end of the article
}

(c) The Author(s). 2018 Open Access This article is distributed under the terms of the Creative Commons Attribution 4.0 International License (http://creativecommons.org/licenses/by/4.0/), which permits unrestricted use, distribution, and reproduction in any medium, provided you give appropriate credit to the original author(s) and the source, provide a link to the Creative Commons license, and indicate if changes were made. The Creative Commons Public Domain Dedication waiver (http://creativecommons.org/publicdomain/zero/1.0/) applies to the data made available in this article, unless otherwise stated. 


\section{Background}

Acne vulgaris is considered as one of the most prevalent skin disease requiring visits to dermatologists. It typically starts in the adolescent age group and resolves naturally also (Dudhiya et al. 2015). Acne vulgaris is a disease of the pilosebaceous unit characterized by seborrhea, comedones, papules, pustules, nodules, and, in few cases, scarring (Layton 2010). Acne not only causes cosmetic problems but it causes social, psychological, and emotional distress as well as self-perception of poor health leading to deteriorating quality of life of patients (Al Robaee 2009). Current treatment modalities for acne mainly target multiple factors contributing to development of acne including topical and systemic retinoids, antimicrobials, and other adjuvant therapies like peeling (Kim and Armstrong 2011). While retinoids and antimicrobials remain the mainstay of conventional treatment of acne, novel adjunctive treatment like chemical peeling, laser, and photodynamic therapy are on rise as patients and clinicians seek to circumvent antibiotic resistance, reduce adverse effect, and employ new technologies in acne care (Ross 2005; Taub 2007).

Chemical peeling is the application of a chemical agent to the skin that causes controlled destruction of part/ whole epidermis with/without dermis leading to exfoliation and removal of superficial lesions followed by rejuvenation of new epidermal and dermal tissues (Khunger 2008). Various chemical peels are available like glycolic acid, salicylic acid, mandelic acid, and lactic acid. Salicylic acid (SA) is a member of a group of compounds known as hydroxy acids, which are widely used for a number of cosmetic indications because of their many important properties (Kornhauser et al. 2010). Salicylic acid has been used as a well-tolerated and safe peeling agent in all skin types in cosmetic dermatology by various researchers. Most of the available literature on chemical peels focuses on its role in skin rejuvenation and the correction of dyschromias. Salicylic acid peels have been widely used in Asian patients since long ago, but very few published literature is there focusing on the efficacy and safety of it in Asian population. Various formulations are available for salicylic acid peels in the market with huge price differences.

Therefore, the present study is planned to study the efficacy of freshly prepared salicylic acid vs. commercially available salicylic acid peel in treatment of acne vulgaris.

\section{Methods}

A randomized open-label study spread over 1 year was carried out in the dermatology department of a tertiary care teaching hospital in Western India. The study protocol was approved by the Human Research Ethics Committee of the institute prior to commencement of study. Permission from the hospital superintendent and head of the dermatology department was also obtained before conducting the study.

\section{Participant selection}

A total 126 patients attending the dermatology outpatient department and diagnosed with acne vulgaris were included in the study.

\section{Inclusion criteria}

Diagnosis of acne was mainly based on clinical examination by the qualified dermatologist. Patients of age 12 years and more for both genders with mild to moderate acne with facial lesions only were included in the study. Only those newly diagnosed and those who did not take any treatment for the last 15 days were included for the study.

\section{Exclusion criteria}

Pregnant and lactating mothers, patients with known history of hypersensitivity reaction to salicylates or aspirin, patients with history of herpes simplex, patients with drug-induced acne, and patients with history of keloid formation were excluded from the study. Patients not willing to participate in the study and not willing to give written informed consent were also excluded.

\section{Study duration}

These 126 patients were enrolled from March 2017 to August 2017. The first examination started in March 2017, and, considering follow-up visits, the last patient was enrolled in May 2017 so that the 12-week follow-up could be completed in August 2017.

\section{Study procedure in detail}

All the patients participating in the study were given a clear explanation about the purpose and nature of the study in the language they understood. Written informed consent was obtained before including them in the study. In the case of a minor, written informed consent from the parent/legal guardian was obtained in addition to assent from the adolescent. All outdoor patients, new as well as old, meeting the inclusion criteria attending the dermatology department were interviewed for the first time on the day of enrollment, and their case sheets were reviewed to gather necessary information-as on that day-to fill up case record forms. Detailed history and examination was carried out by the treating dermatologist. Details of the symptoms, duration, site, and type of lesions; any keloidal tendencies in the patient or in the family; and presence of viral infection, local tumors, and evolving dermatoses were noted. Counting of lesions was done in good natural light with the help of a hand lens. Acne grading was done using lesion count: grade 1 (total number of lesions $<10 / 100 \mathrm{~cm}^{2}$ ), grade $2(10-20 /$ 
$\left.100 \mathrm{~cm}^{2}\right)$, grade $3\left(20-30 / 100 \mathrm{~cm}^{2}\right)$, and grade $4(>30 /$ $100 \mathrm{~cm}^{2}$ ) (Tutakne and Chari 2003).

Evaluation of active acne was done using a method devised by Michaelsson and colleagues (Table 1) (Michaelsson et al. 1977). By multiplying the number of each type by its severity index and adding each sum, a total acne score was obtained. Assessment of acne lesions was done at baseline ( 0 weeks) and at each visit (2, $4,6,8,10$, and 12 weeks).

\section{Randomization and group allocation}

All patients were randomly assigned into groups A and $B$ using random number table.

Group A: Patients with acne vulgaris treated with commercially available $30 \%$ salicylic acid peeling

Group B: Patients with acne vulgaris treated with freshly prepared 30\% salicylic acid peeling (which was prepared by adding $3 \mathrm{~g}$ of salicylic acid powder into $10 \mathrm{ml}$ of denatured spirit)

\section{Intervention-SA peel}

Six peeling sessions were conducted for each group at weeks $0,2,4,6,8$, and 10 . Patients were also called at the end of the 12th week for follow-up visit, but peeling was not applied on that session. At the first visit of enrollment, hypersensitivity testing was done in all patients. A hypersensitivity test with $10 \%$ SA peel both commercially available and freshly prepared was performed on a small $1-\mathrm{cm}$ area in the right retro-auricular area. The patients were reviewed after 1 week, and if they tolerated the peel well, they were taken up for full-face peels. Patients were asked to first wash their face with water then asked to lie down in a $45^{\circ}$ semi-reclining position with eyes closed. All patients were given a surgical cap to pull back their hair and cover the ears. Degreasing was done by scrubbing with cotton gauze soaked with spirit, followed by one soaked with cleansing lotion. Sensitive areas of the face like the lips and nasolabial folds were protected with a thin layer of petrolatum. Commercially or freshly prepared SA peel will be then applied over the face using a fan-shaped

Table 1 Evaluation of active acne*

\begin{tabular}{|c|c|c|}
\hline Lesion & Severity & Index definition* \\
\hline Comedone & 0.5 & $\begin{array}{l}\text { Horny follicular plug and pinhead-sized follicular } \\
\text { papules }\end{array}$ \\
\hline Papule & 1.0 & Infiltrated papules 2-8 mm \\
\hline Pustule & 2.0 & Pustules $42 \mathrm{~mm}$ with surrounding inflammation \\
\hline Infiltrate & 3.0 & $\begin{array}{l}\text { Nodules and infiltrates: } 48 \mathrm{~mm} \text { and coalescent } \\
\text { papules where individual papules cannot be } \\
\text { distinguished }\end{array}$ \\
\hline Cyst & 4.0 & $\begin{array}{l}\text { Lesions where infiltrate has broken down to form } \\
\text { discharging cyst }\end{array}$ \\
\hline
\end{tabular}

*Michaelsson et al. (1977); Cosmetic Surgery National Data Bank (2003) sable brush in a predetermined clockwise manner starting over the forehead, right cheek, chin, left cheek, nose, upper lip, and lastly the infraorbital areas, taking 30 to $35 \mathrm{~s}$ to accomplish and using approximately 0.8 to $1 \mathrm{ml}$ solution per session. With SA peeling, the patients experience a stinging sensation that usually lasted for 3 to $5 \mathrm{~min}$. After the cessation of this stinging sensation, most patients developed a uniform white crystalline precipitate, "pseudofrost," in the peeled areas (indicating the deposition of salicylic acid after its hydroethanolic vehicle had volatilized) which was considered as the end point of peeling. In patients who did not develop the pseudofrost, the cessation of the stinging sensation was considered the end point. The total duration of the peeling sessions varied from 3 to $5 \mathrm{~min}$ with SA peeling. As soon as the end point was reached, the peel was neutralized by asking the patients to wash their faces with copious amounts of cool tap water. Patients were then asked to pat, and not rub, the face dry. The patients were asked to apply a sunscreen with a sun protection factor (SPF) of greater than 30 on their faces before leaving the dermatology department. Patients were allowed to go home with instructions to apply a non-comedogenic moisturizing cream if the facial skin felt too dry, to avoid or minimize sun exposure, and to apply sunscreen whenever exposed to the sun. They were cautioned not to apply any cream or face wash containing AHAs, salicylic acid, or retinoids. All the patients were followed up every 15 days till 3 months and improvement in acne was recorded.

\section{Outcome measures}

The treating physician made an objective assessment of the changes in active acne lesions, post-acne scarring, and hyperpigmentation at each visit. For the objective assessment, each type of lesion was counted in number like number of comedones, papules, pustules, and cyst, and standard deviation for the mean of each lesion count was also calculated. Reduction/change in the number of lesion count was noted, and time to achieve this reduction was also compared between the two groups. For post-acne scarring and hyperpigmentation, clinical examination in appropriate light was carried out by two different qualified dermatologists. The reduction in post-acne scarring and hyperpigmentation was evaluated clinically by both dermatologists consensually, and then time to achieve this reduction was also noted. In cases of conflict of opinion among two dermatologists, the clinical examination by the head of the dermatology department was carried out and results were recorded accordingly. The patient's subjective assessment was also made using a $100-\mathrm{cm}$ visual analog scale. It was graded as excellent (> $80 \%)$, good $(60-80 \%)$, average $(30-60 \%)$, poor $(<30 \%)$, no change, and worse. Clinical photographs using standardized positioning were taken at baseline and at 4,8 , and 12 weeks. 
Table 2 Baseline characteristics of study patients with acne $(n=123)$

\begin{tabular}{|c|c|c|c|c|}
\hline Characteristic & $\begin{array}{l}\text { No. of patients in commercially } \\
\text { available SA peel group; } n=60(\%)\end{array}$ & $\begin{array}{l}\text { No. of patients in freshly prepared SA } \\
\text { peel group; } n=63(\%)\end{array}$ & $\begin{array}{l}\text { Total } \\
n=123(\%)\end{array}$ & $\begin{array}{l}\text { Chi-square test } \\
(P \text { value })\end{array}$ \\
\hline \multicolumn{5}{|l|}{ Age in years } \\
\hline $12-20$ & 24 & 18 & $42(34.15)$ & \\
\hline $21-30$ & 30 & 38 & $68(55.28)$ & 0.05 \\
\hline $31-40$ & 6 & 7 & $13(10.57)$ & \\
\hline Mean age (mean $\pm \mathrm{SD})$ & $23.47 \pm 5.62$ & $22.99 \pm 6.35$ & - & 0.62 \\
\hline Gender (M:F) & $0.62: 1$ & $0.66: 1$ & - & 0.54 \\
\hline \multicolumn{5}{|l|}{ Skin type } \\
\hline 2 & 2 & 3 & $5(4.07)$ & 0.71 \\
\hline 3 & 21 & 25 & $46(37.40)$ & 0.64 \\
\hline 4 & 34 & 30 & $64(52.03)$ & 0.42 \\
\hline 5 & 3 & 5 & $8(6.50)$ & 0.5 \\
\hline \multicolumn{5}{|l|}{ Common presentation } \\
\hline Papules & 60 & 63 & 123(100) & 0.45 \\
\hline Pustules & 12 & 16 & $28(22.76)$ & 0.68 \\
\hline Nodules & 6 & 9 & $15(12.20)$ & 0.42 \\
\hline Comedones & 56 & 54 & $110(89.43)$ & 0.53 \\
\hline \multicolumn{5}{|l|}{ Grading of acne } \\
\hline Grade 1 & 23 & 27 & 50 & 0.08 \\
\hline Grade 2 & 32 & 30 & 62 & 0.06 \\
\hline Grade 3 & 5 & 4 & 9 & 0.68 \\
\hline Grade 4 & 0 & 2 & 2 & 0.53 \\
\hline
\end{tabular}

Chi-square test; $P$ value $<0.05$ is considered significant

$S D$ standard deviation, $M: F$ male to female ratio

\section{Statistical analysis}

All data were analyzed with the help of Microsoft excel 2010. Data were represented as actual frequency, mean, percentage, and standard deviation as appropriate. Chi-square test was used for analysis and association of qualitative data. Unpaired $t$ test was used for comparison between the groups, and paired $t$ test was used for within-group comparisons. $P$ values $<0.05$ were considered significant.

\section{Results}

Out of the total 126 patients enrolled, 123 completed the study while the rest three patients were lost to follow-up. The mean age of the patients was $23.47 \pm 5.62$ and $22.99 \pm 6.35$ years in the commercially and freshly prepared SA groups, respectively. $55.28 \%$ of patients belong to 21-30 years of age with female preponderance. Baseline details of the study participants are shown in Table 2.

Onset of acne occurred between the ages of 14 and 16 in $52.7 \%$ of the patients. The interval between onset of acne and scarring was 2 to 4 years in $57.4 \%$ of patients.

\section{Objective assessment}

Objective evaluation of treatment outcomes done by the treating physician revealed the following. As shown in Table 3, there was reduction of both non-inflammatory and inflammatory acne with commercially available SA

Table 3 Objective evaluation of acne after peeling with commercially available SA peel

\begin{tabular}{|c|c|c|c|c|}
\hline Morphology of lesions & $\begin{array}{l}\text { Commercially available SA peel } \\
\text { (day 0) (mean) }\end{array}$ & $\begin{array}{l}\text { Commercially available SA peel } \\
\text { (at } 12 \text { week) (mean) }\end{array}$ & Mean percentage of reduction & $P$ value ${ }^{*}$ \\
\hline Comedones & $6.27+2.4$ & $1.24+0.79$ & $88.45+0.15$ & 0.002 \\
\hline Papules & $7.11+4.35$ & $1.58+0.6$ & $89.16+0.15$ & 0.01 \\
\hline Pustules & $2.06+1.8$ & $0.17+0.37$ & $31.47+0.45$ & 0.06 \\
\hline Nodules & $1.04+0.23$ & $0.04+0.2$ & $50.0+0.22$ & 0.5 \\
\hline
\end{tabular}

*Paired $t$ test; $P<0.05$ was considered significant 


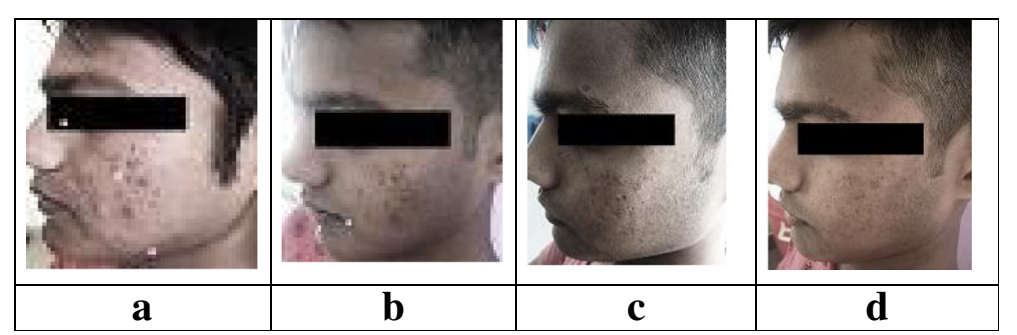

Fig. 1 Efficacy of commercially available salicylic acid peel a at baseline, b at 4 weeks, $\mathbf{c}$ at 8 weeks, and $\mathbf{d}$ at 12 weeks

peel. After six sessions, the reduction in average number of comedones was $88.45 \%(P=0.002)$, reduction in inflammatory papules was $89.16 \%(P=0.01)$, and reduction in pustules was $31.47 \%(P=0.06)$ and nodules/cysts were reduced by $50 \%(P=0.5)$. On clinical examination of the patient, it showed improvement in superficial scarring and skin texture. It also resolved post-acne hyperpigmentation to some extent (Fig. 1a-d).

Table 4 shows response of the patients with freshly prepared salicylic acid peel. Reduction of both non-inflammatory and inflammatory acne was observed. After six sessions, the reduction in average number of comedones was $89 \%(P=0.0001)$, reduction in inflammatory papules was $90.36 \%$, with $P=0.0001$; pustules were reduced by $28.3 \%(P=0.05)$ and nodules were reduced by 96\% $(P=0.05)$. On clinical examination, it showed improvement in post-acne hyperpigmentation and overall appearance. It also resolved post-acne scarring to some extent (Fig. 2a-d).

\section{Total acne score}

Although both of the agents led to highly significant $(P<$ 0.001 ) improvement in the total acne score, freshly prepared SA peel showed improvement significantly earlier at 6 weeks. The change in total acne score (week 0 to week 12) was $78.3 \%$ with commercially available peel and $80.1 \%$ with freshly prepared SA peel $(P>0.05)$ (Table 5$)$.

\section{Subjective assessment}

The visual analog scale scores as assessed by the patient are shown in Table 5. Mean VAS scores were 84.3 and 90.1 in the commercially available and freshly prepared
SA peel groups, respectively, which were statistically significant $(P=0.05)$.

Acne lesions at baseline and after 4, 8, and 12 weeks for both the commercially available and freshly prepared SA peel groups are shown in Figs. 1 and 2 respectively.

\section{Discussion}

Acne is a one of the most common disease encountered in the dermatology department all over the world. Topical agents such as clindamycin, erythromycin, benzoyl peroxide, and retinoic acid have been mainstays in the treatment of acne vulgaris for the past two decades (Al Robaee 2009; Kim and Armstrong 2011; Ross 2005; Taub 2007), but new modalities like chemical peelings, laser, and other minimally invasive technologies are increasingly used nowadays. According to statistics from the American Society for Aesthetic Plastic Surgery, a total 495,415 chemical peels were performed in 2002 (Cosmetic Surgery National Data Bank 2003). The chemical peel is among the top 5 cosmetic procedures performed in the USA, and it has been increasingly used in developing countries like India. Several researchers have studied the role of salicylic acid as a superficial chemical peeling agent. There has been an increasing trend toward the use of more superficial chemical peels in the treatment of actinic damage and pigmentation. This study was aimed at comparative evaluation of efficacy of commercially available salicylic acid peel with freshly prepared salicylic acid peel in treatment of acne vulgaris in a tertiary care teaching hospital.

In this study, a maximum number of patients was from the age group of 21-30 years with female preponderance. The findings are well coinciding with the

Table 4 Objective evaluation of acne after peeling with freshly prepared SA peel

\begin{tabular}{lllll}
\hline Morphology of lesions & $\begin{array}{l}\text { Commercially available SA } \\
\text { peel (day 0) (mean) }\end{array}$ & $\begin{array}{l}\text { Commercially available SA peel } \\
\text { (at 12 week) (mean) }\end{array}$ & Mean percentage of reduction & $P$ value* \\
\hline Comedones & $6.18 \pm 2.45$ & $0.67 \pm 0.70$ & $89.00 \pm 0.21$ & 0.0001 \\
Papules & $7.29 \pm 1.43$ & $0.10 \pm 0.74$ & $90.36 \pm 0.13$ & 0.05 \\
Pustules & $5.91 \pm 1.05$ & $0.20 \pm 0.34$ & $28.3 \pm 0.42$ & 0.05 \\
Nodules & $1.04 \pm 0.25$ & $0.01 \pm 0.00$ & $96.0 \pm 0.42$ & 0.05 \\
\hline
\end{tabular}

*Paired $t$ test; $P<0.05$ was considered significant 


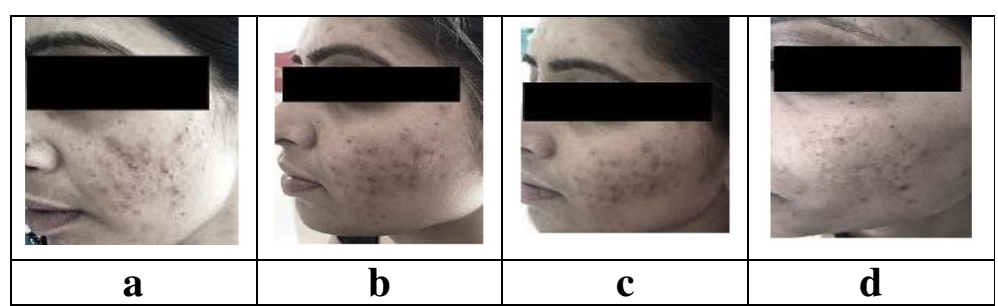

Fig. 2 Efficacy of freshly prepared salicylic acid peel a at baseline, $\mathbf{b}$ at 4 weeks, $\mathbf{c}$ at 8 weeks, and $\mathbf{d}$ at 12 weeks

studies by Atzori et al. (1999) and Sharma et al. (2016) and other available literature. This is because of hormonal changes at adolescent age which are more pronounced in the female gender. Moreover, females are more conscious about cosmetic appearance in India as compared to males, making more females visit the dermatology department.

SA peel has been established as an effective treatment modality in this study. Both commercially available and freshly prepared SA peels were effective in reducing the number of comedones and papules but less effective in treating nodules and pustules. However, a few studies have used salicylic acid for treatment of acne. Lee and Kim evaluated the use of 30\% salicylic acid in treatment of acne in 35 Asian patients (Lee and Kim 2003). The salicylic acid was used fortnightly for 12 weeks. They found a significant decrease in mean total facial lesion count, non-inflammatory lesions, and mean acne grade reduction at the end of treatment. Grimes used two 20\% and three $30 \%$ salicylic acid peels at fortnightly intervals in 25 dark-skinned patients with different dermatoses, out of whom 9 had acne vulgaris (Grimes 1999). Moderate (51-
$75 \%)$ to significant (>75\%) clearing of acne was seen in $89 \%$ of patients. Non-inflammatory and inflammatory lesions were seen to clear faster than would ordinarily have occurred with traditional therapy.

Salicylic acid is a betahydroxy acid that has a phenolic ring in its chemical structure (Kim 2005). It is an excellent keratolytic agent by way of its ability to dissolve intercellular cement thereby reducing corneocyte adhesion (Lee and Kim 2003; Kessler et al. 2008). Due to its lipophilicity, it has better penetration into the pilosebaceous unit. This property of salicylic acid accounts for its strong comedolytic effect and its utility in the treatment of acne (Lee and Kim 2003; Kim 2005; Hashimoto et al. 2008; Kligman and Kligman 1997a; Ahn and Kim 2006; Lai and Mercurio 2009). The anti-inflammatory activity of SA makes it useful in rapidly decreasing facial erythema (Berger 1997).

Because both of the preparations of peeling agents are superficial peels, they serve only to resurface the upper layers of the epidermis. Through an indirect, as-yet-unknown mechanism, it stimulates the dermal fibroblasts to deposit more collagen, elastin, and glycosaminoglycans in the

Table 5 Comparison of outcomes in commercially vs. freshly prepared SA peels

\begin{tabular}{|c|c|c|c|c|c|c|}
\hline & \multicolumn{2}{|l|}{ Commercially available SA peel } & \multicolumn{2}{|l|}{ Freshly prepared SA peel } & \multirow[b]{2}{*}{$\begin{array}{l}P \text { value for total } \\
\text { acne score* }\end{array}$} & \multirow[b]{2}{*}{$\begin{array}{l}P \text { value for } \\
\text { VAS }^{* *}\end{array}$} \\
\hline & $\begin{array}{l}\text { Objective: mean improvement in } \\
\text { total acne score }\end{array}$ & $\begin{array}{l}\text { Subjective: } \\
\text { VAS }\end{array}$ & $\begin{array}{l}\text { Objective: mean improvement in } \\
\text { total acne score }\end{array}$ & $\begin{array}{l}\text { Subjective: } \\
\text { VAS }\end{array}$ & & \\
\hline At day 0 & - & - & - & - & - & - \\
\hline $\begin{array}{l}\text { At } \\
2 \text { weeks }\end{array}$ & 25.4 & 30 & 27.5 & 40 & 0.08 & 0.07 \\
\hline $\begin{array}{l}\text { At } \\
4 \text { weeks }\end{array}$ & 30.1 & 51 & 38.4 & 65 & 0.06 & 0.05 \\
\hline $\begin{array}{l}\text { At } \\
6 \text { weeks }\end{array}$ & 36.8 & 67.5 & 50 & 70.4 & 0.04 & 0.63 \\
\hline $\begin{array}{l}\text { At } \\
8 \text { weeks }\end{array}$ & 50.4 & 78.3 & 68 & 81.6 & 0.05 & 0.57 \\
\hline $\begin{array}{l}\text { At } \\
10 \text { weeks }\end{array}$ & 73.3 & 81 & 75.8 & 89.5 & 0.8 & 0.05 \\
\hline \multirow{2}{*}{$\begin{array}{l}\text { At } \\
12 \text { weeks }\end{array}$} & 78.3 & 84.3 & 80.1 & 90.1 & 0.05 & 0.05 \\
\hline & $P<0.05^{\#}$ & $P<0.05^{\#}$ & $P<0.05^{\#}$ & $P<0.05^{\#}$ & & \\
\hline
\end{tabular}

The italics $P<0.05$ value was considered significant for the analysis

*Unpaired $t$ test for comparison of the commercially available and freshly prepared SA peel groups

${ }^{*}$ Chi-square test for comparison of VAS between the commercially available and freshly prepared SA peel groups

"Within-group comparison; paired $t$ test 
papillary dermis. A more orderly and parallel arrangement of the fibers is also seen with use of SA peel (Kligman and Kligman 1997b). Thus, a gradual and slight decrease in the number of superficial scars and a decrease in the depth of deeper scars are observed. In addition, Ahn and Kim (2006) showed salicylic acid to have a whitening effect on the skin. This effect was seen in the present study too, with patients reporting diffuse lightening of their facial complexion.

On analyzing subjective assessment for peels, the mean visual analog scale scores were significantly higher for the freshly prepared SA peel group rather than the commercially available SA peel in this study. Acetyl salicylic acid is an easily available laboratorygrade ingredient and also one of the over-the-counter medications for pain and fever as "aspirin." This study has shown that if properly prepared considering the concentration of the peel, freshly prepared peels are equally efficacious as the commercially available chemical SA peel in terms of both subjective and objective outcome evaluation. Caution is required and skill has to be learned for preparing fresh SA peel like measuring the exact quantity of acetyl salicylic acid, its proper dilution in appropriate vehicle, and its use on the patients.

This study has established the equivalence in therapeutic efficacy of both commercially available and freshly prepared SA peels in treatment of acne vulgaris. To the best of our knowledge, this is the kind of first published study comparing freshly prepared peels and commercially available peels. Although homemade freshly prepared peels are routinely used as homemade remedies in India since long ago, its comparison with the commercially available preparations was less studied. The single center and the limited number of patients are among the few limitations of the study. Also, different types of formulations like gel base, cream, and solution may differ in some characteristics and may affect the outcome of peeling procedure when commercially available preparations are used which could not be studied here. Larger studies with multiple centers and longer follow-up duration are required in this area.

\section{Conclusions}

Chemical peeling is used increasingly for treatment of acne vulgaris either alone or in combination with traditional therapy like topical antimicrobial agents, benzyl peroxide, 0 and retinoic acid. This study has shown that if properly prepared considering the concentration of the peel, freshly prepared peels are equally efficacious as the commercially available chemical SA peel in terms of both subjective and objective outcome evaluation. Total acne scores were reduced significantly and VAS showed significant more patients' satisfaction with the freshly prepared peel. Chemical peeling with the freshly prepared SA peel can be an affordable treatment option performed in any dermatologist's office, if caution is required while preparing the peel. Postgraduate students and dermatologists can be trained in preparing and using freshly prepared SA peel which can serve as an effective treatment option.

\section{Acknowledgements \\ The authors would like to thank Dr. Bipin Nayak, Hospital Superintendent, for allowing the research in the Department of Dermatology, Civil Hospital, Gandhinagar - a tertiary care teaching rural hospital in Western India. \\ Availability of data and materials \\ Study data can be obtained from the corresponding author Dr. Purna Pandya, in any case of any query.}

\section{Authors' contributions}

PP has designed the idea and concept of the study, performed the salicylic acid peeling procedure, analyzed the data, and interpreted the results. DR has performed procedures on most patients and gathered the data of the patients. IP has performed the procedure of peeling on patients, collected the data, analyzed the data, and prepared the results. GS has helped in the statistical analysis of the data, results analysis, and writing of the manuscript. RS has helped in the study design, data analysis, and writing of the manuscript. BP has helped in the interpretation of the data and writing of the manuscript. All authors read and approved the final manuscript.

\section{Ethics approval and consent to participate}

The study protocol was approved by the Institutional Ethics Committee, GMERS Medical College, Gandhinagar, approval letter no: GMERSMCG/IEC/ 13/2017 dated 1 March 2017.

All the participants were given a clear explanation about the nature and purpose of the study in the language they understood, and written informed consent was obtained before enrolling the participants for the study. In the case of patients less than 18 years, assent of the minor was also obtained in addition to the informed consent from the parent or legal guardian.

\section{Consent for publication}

Informed written consent was received for publication of the manuscript and figures. Written informed consent was obtained from the patient for publication of their individual details and accompanying images in this manuscript. The consent form is held by the authors and is available for review by the Editor-in-Chief.

\section{Competing interests}

The authors declare that they have no competing interests.

\section{Publisher's Note}

Springer Nature remains neutral with regard to jurisdictional claims in published maps and institutional affiliations.

\section{Author details}

${ }^{1}$ Department of Dermatology, GMERS Medical College, Gandhinagar, Gujarat, India. ${ }^{2}$ Department of Dermatology, SBKS Medical Institute and Research Centre, Piparia, Waghodiya, Vadodara, Gujarat, India. ${ }^{3}$ Department of Oral and Maxillofacial Surgery, NIIMS Dental College, Jaipur, Rajasthan, India.

${ }^{4}$ Department of Pharmacology, GMERS Medical College, Gandhinagar, Gujarat, India.

Received: 2 June 2018 Accepted: 28 September 2018

Published online: 22 October 2018

\section{References}

Ahn $\mathrm{HH}, \mathrm{Kim} \mathrm{H}$. Whitening effect of salicylic acid peels in Asian patients. Dermato Surg. 2006;32:372-5. 
Al Robaee AA. Assessment of general health and quality of life in patients with acne using a validated generic questionnaire. Acta Dermatovenerol Alp Panonica Adrait. 2009;18(4):157-64.

Atzori L, Brundu MA, Orru A, Biggio P. Glycolic acid peeling in the treatment of acne. J Eur Acad Dermatol Venereol. 1999;12(2):119-22.

Berger R. Initial studies show salicylic acid promising as antiaging preparation. Cosmet Dermatol. 1997;10:31-2

Cosmetic Surgery National Data Bank. 2002 Statistics. New York, NY: American Society for Aesthetic Plastic Surgery; 2003.

Dudhiya S, Shah RB, Agrawal P, Shah A, Date S. Efficacy and safety of clindamycin gel plus either benzoyl peroxide gel or adapalene gel in the treatment of acne: a randomized open-label study. Drugs Ther Perspect. 2015. https://doi. org/10.1007/s40267-015-0208-y.

Grimes PE. The safety and efficacy of salicylic acid chemical peels in darker racialethnic groups. Dermatol Surg. 1999;25:18-22.

Hashimoto Y, Suga Y, Mizuno Y, Hasegawa T, Matsuba S, Ikeda S, et al. Salicylic acid peels in polyethylene glycol vehicle for the treatment of comedogenic acne in Japanese patients. Dermatol Surg. 2008;34:276-9.

Kessler E, Flanagan K, Chia C, Rogers C, Glaser DA. Comparison of alpha and beta hydroxyl acid chemical peels in the treatment of mild to moderately severe facial acne vulgaris. Dermatol Surg. 2008;34:45-50.

Khunger N. Standard guidelines of care for chemical peels. Indian J Dermatol Venerol Leprol. 2008;74:S5-S12.

Kim IH. Salicylic acid peel (acne peel). Hong Kong J Dermatol Venereol. 2005;13:83-5.

Kim RH, Armstrong AW. Current state of acne treatment: highlighting lasers, photodynamic therapy, and chemical peels. Dermatol Online J. 2011;17(3):2.

Kligman D, Kligman AM. Salicylic acid as a peeling agent for the treatment of acne. Cosmetic Dermatol. 1997a;10:44-7.

Kligman D, Kligman AM. Salicylic acid as a peeling agent for the treatment of acne. Cosmet Dermatol. 1997b;10:44-7.

Kornhauser A, Coelho SG, Hearing VJ. Applications of hydroxy acids: classification, mechanisms, and photoactivity. Clin Cosmet Investig Dermatol. 2010;3:135-42.

Lai KW, Mercurio MG. Update on the treatment of acne vulgaris. J Clin Outcomes Manag. 2009;16:115-26.

Layton AM. Disorders of sebaceous glands. In: Burns T, Breathnach S, Cox N, Griffith C, editors. Rook's Textbook of Dermatology. 8th ed. Vol 2, vol. 42. Oxford: Blackwell publishers; 2010. p. 17.

Lee HS, Kim IH. Salicylic acid peels for the treatment of acne vulgaris in Asian patients. Dermatol Surg. 2003:29:1196-9.

Michaelsson G, Zuhlin L, Vahlquist A. Effects of oral zinc and vitamin A in acne. Arch Dermatol. 1977;113:31-6.

Ross EV. Optical treatments for acne. Dermatol Ther. 2005;18(3):253-66.

Sharma P, Shah A, Dhillon AS. Study of glycolic acid and salicylic acid peels as a sole therapy in treatment of acne vulgaris. Int J Med Res Rev. 2016;4(12): 2205-10 doi: 10.17511 /ijmrr. 2016.112.21.

Taub AF. Procedural treatments for acne vulgaris. Dermatol Surg. 2007:33(9):1005-26.

Tutakne MA, Chari KVR. Acne, rosacea and perioral dermatitis. In: Valia RG, Valia AR, editors. IADVL textbook and atlas of dermatology. 2nd ed. Mumbai: Bhalani publishing House; 2003. p. 689-710.

Ready to submit your research? Choose BMC and benefit from:

- fast, convenient online submission

- thorough peer review by experienced researchers in your field

- rapid publication on acceptance

- support for research data, including large and complex data types

- gold Open Access which fosters wider collaboration and increased citations

- maximum visibility for your research: over $100 \mathrm{M}$ website views per year

At $\mathrm{BMC}$, research is always in progress.

Learn more biomedcentral.com/submissions 